John M.G. Barclay

\title{
Pauline Churches and Diaspora Jews
}

[Die paulinischen Gemeinden und die jüdische Diaspora. Sozialgeschichtliche Studien zur Bildung der frühchristlichen Identität .]

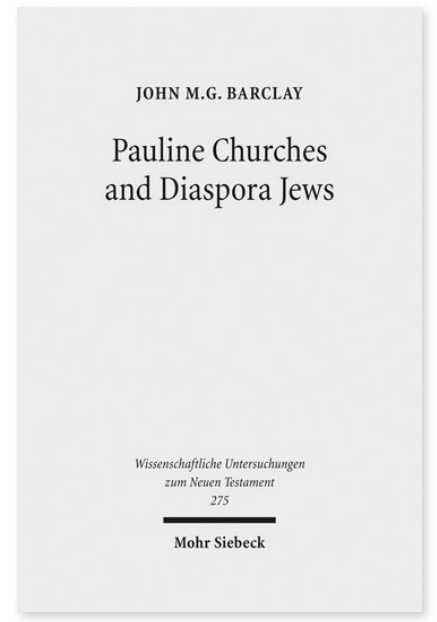

2011. XII, 454 Seiten. WUNT I 275

ISBN 978-3-16-151774-7

DOI 10.1628/978-3-16-151774-7

eBook PDF 159,00€
Veröffentlicht auf Englisch.

Die Gemeinden, die Paulus in den Städten rund um das Mittelmeer gründete, waren den an den gleichen Orten entstandenen Synagogen der jüdischen Diaspora in vielen Aspekten sehr ähnlich. John M.G. Barclay vergleicht beide in den hier gesammelten sozialgeschichtlichen Aufsätzen und arbeitet so den langen und vielschichtigen Prozess des Entstehens einer frühchristlichen Identität heraus, die sich über mehrere Generationen hinweg entwickelte. Der Autor geht diesem Prozess nach und konzentriert sich dabei besonders auf die paulinische Tradition. Die frühchristliche Identität erweist sich hier als zerbrechlich, umstritten, häufig nicht klar definiert, kreativ in sozialen Belangen und vielfältig in ihrer Art, sich auszudrücken: in ihrer Praxis, ihren Konventionen, ihren sozialen Angelegenheiten und ihren Sprachen stellen sich die paulinischen Gemeinden als mal konformistisch und dann wieder als radikal innovativ dar.

John M.G. Barclay Born 1958; undergraduate in Cambridge (Classics and Theology); 1986 PhD in Cambridge; since 2003 Lightfoot Professor of Divinity at Durham University.
Jetzt bestellen:

https://mohrsiebeck.com/buch/pauline-churches-and-diaspora-jews-9783161517747?no_cache=1 order@mohrsiebeck.com

Telefon: +49 (0)7071-923-17

Telefax: $+49(0) 7071-51104$ 